\title{
Polyurea Elastomers: Astute Choice of Building Blocks for Obtaining Predictable Material Properties
}

\author{
Manorama Tripathi, Surekha Parthasarathy and Prasun Kumar Roy* \\ Centre for Fire, Explosive and Environment Safety, India
}

ISSN: 2576-8840

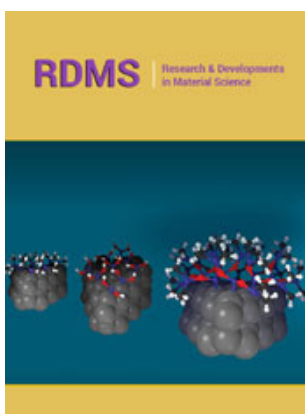

*Corresponding author: Prasun Kumar Roy, Centre for Fire, Explosive and Environment Safety, India

Submission: 䧳 November 27, 2019

Published: 侮 December 09, 2019

Volume 12 - Issue 3

How to cite this article: Manorama Tripathi, Surekha Parthasarathy, Prasun Kumar Roy. Polyurea Elastomers: Astute Choice of Building Blocks for Obtaining Predictable Material Properties. Res Dev Material Sci. 12(4).RDMS.000791.2019. DOI: 10.31031/RDMS.2019.12.000791

Copyright@ Prasun Kumar Roy, This article is distributed under the terms of the Creative Commons Attribution 4.0 International License, which permits unrestricted use and redistribution provided that the original author and source are credited.

\section{Abstract}

Polyurea is a reaction product of an isocyanate with an amine and protective coatings based on polyurea are finding extensive application in diverse fields, especially towards protection of underlying structures for any particular isocyanate, the properties of the final product can be tailored by tweaking the constituents of the amine resin blend, especially chain extenders, chain length and crosslinker. In this review, we explicate the effect of various factors viz. soft segment length, type and concentration of chain extender and crosslinker on the material properties of polyurea.

\section{Mini Review}

Polyurea is a relatively new entrant in the field of protective coatings, particularly for improved blast resistance and ballistic performance [1,2]. These elastomers are well known for their short 'curing' times, excellent durability and exceptional adhesion to a variety of surfaces. In view of the rapid kinetics of isocyanate-amine reaction, conventional techniques like brush coating cannot be employed to form coatings [3]. Polyurea is commercially available as a two-part formulation: Side A, an isocyanate prepolymer duly diluted with a cyclic organic carbonate for viscosity matching with Side B, which is a blend of amines. For practical processing, the isocyanate and amine are reacted just prior to being sprayed through the nozzle over any surface, which need to be coated. Seamless polyurea coatings can be formed practically instantaneously, in a matter of just a few seconds.

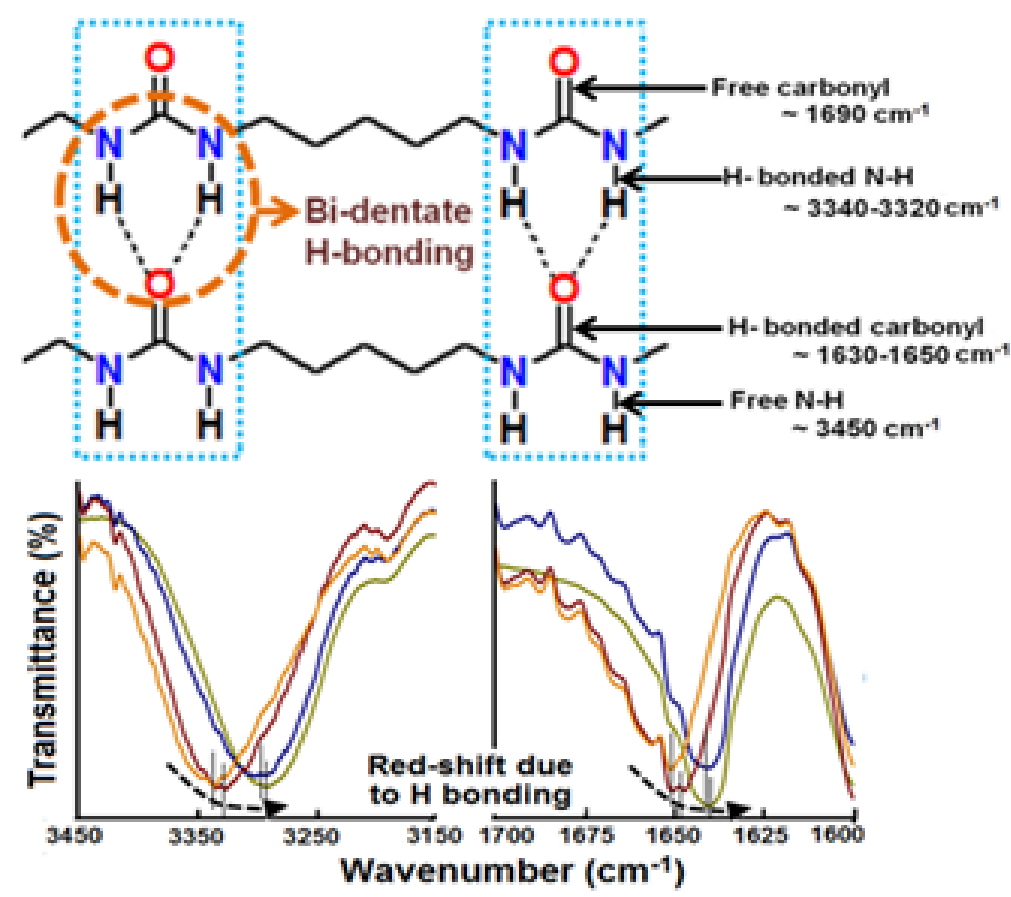

Figure 1: Bidentate hydrogen bonds between polyurea chains [6]. 
The material properties of polyurea are a manifestation of its phase segregated microstructure, which is formed of distinct "hard" and "soft" domains [4]. The intermolecular bidentate H-bonds between polymeric chains bestow excellent mechanical properties to this polymer. A significant red shift due to H-bonding has been observed in the regions associated with the carbonyl $(>C=0)$ and amine (N-H) frequencies (Figure 1). The resin (side B) is a blend of a long chain diamine, a chain extender and a crosslinker amongst other additives like adhesion promoters and colourants. It is extremely valuable to understand how these constituents affect the internal microstructure of the polymer, which subsequently reflect on its mechanical properties. This knowledge can prove beneficial in the preparation of formulations with predictable properties. For maintaining a stoichiometric balance, the number of individual components is first estimated as follows:

$$
m_{i s o} \cdot n_{e q, i s o}=\left[m_{a \min e, 1} \cdot n_{e q, a \min e, 1}+m_{a \min e, 2} \cdot n_{e q, a \min e, 2}\right] i_{N C O}
$$

where, $m, n$ and $i_{\text {NCO }}$ refers to the mass, equivalent number and the isocyanate index respectively. In addition, for formulating a spray processable composition, there are additional two major constraints with respect to the isocyanate-amine volume and viscosity equivalence, i.e. $v_{\text {isocyanate }}=v_{\text {amine }}$ and $\eta_{\text {isocyanate }}=\eta_{\text {amine }}$.

It is well known that thermodynamic incompatibility between the hard and soft segments results in the formation of a phase segregated structure. The long chain amine is more often than not selected from the class of amine terminated polyethers, the molecular weight of which can affect the properties substantially.
The hard segments of urea linkages are extensively H-bonded and serve as reversible physical cross-links as well as reinforcing fillers [2,5]. The chain extender brings the urea linkages closer to each other, thereby increasing the probability of H-bonding in the polymer. The crosslinker is usually chosen from the class of trifunctional amines, which link the chains together and increases the strength and stiffness of the coating [6].

\section{Selection of long chain amines: Effect of increasing soft segment length}

The glass transition phenomenon in polyurea occurs at subambient temperatures, which is a result of the movement of the soft polyether chains which form its soft segments [2]. Studies on nonchain extended polyureas containing poly(tetramethyleneoxide) based soft segments highlight the inverse relation of the "service window" of polyurea with increasing soft segment length [7]. In general, the tensile strength decreases and the "elongation at failure" increase with increasing soft segment length. These have been revealed by studies performed on spray coated polyureas prepared from MDI based isocyanate prepolymer and polypropylene oxide-based amines. Also, the low-temperature $\mathrm{T}_{\mathrm{g}}$ associated with the segmental motions of the soft segments was found to decrease with increasing its chain length $\left(-43^{\circ} \mathrm{C}\right.$, M.wt $\sim 2000$ to $-10{ }^{\circ} \mathrm{C}, \mathrm{M}$. wt $\sim 230$ ). Dynamic Mechanical analysis (DMA) further confirm that the frequency associated with the arresting of segmental motions increase substantially with increasing 'soft segments' [8]. A pictorial representation on how the soft segment chain length affects the material properties is presented in Figure 2.

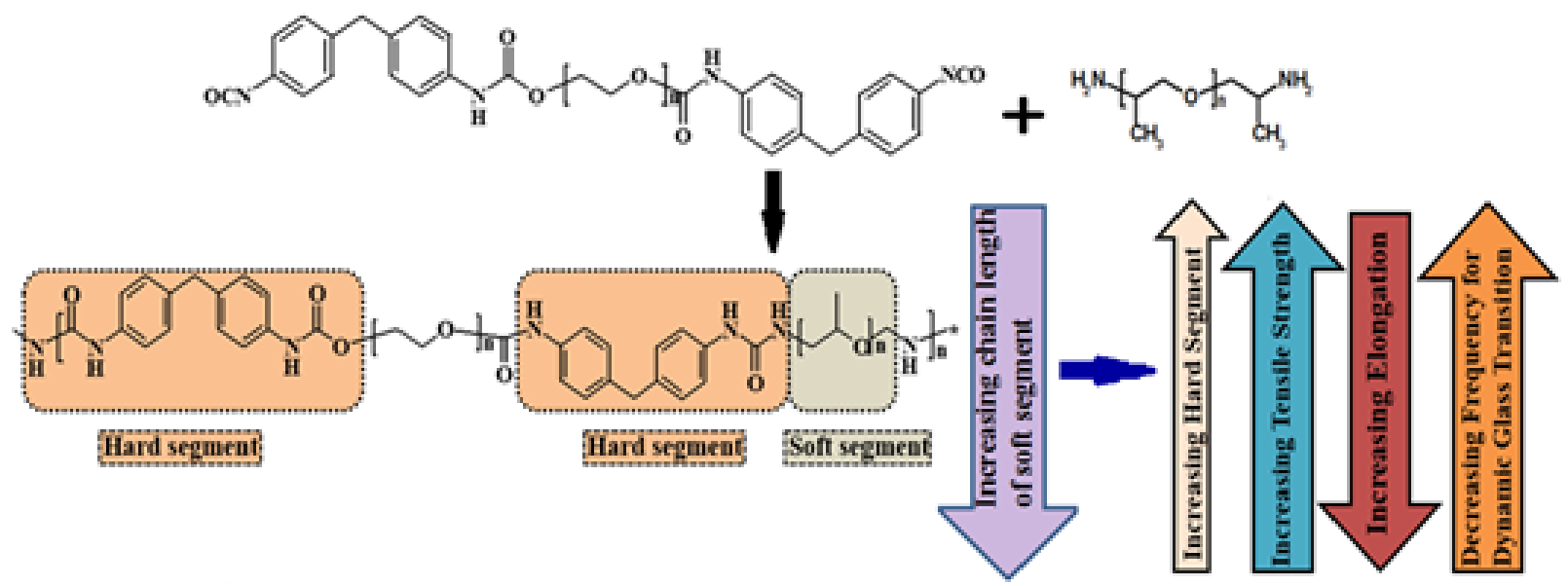

Figure 2: How the chain length of amine affects the mechanical properties of polyurea [8].

\section{Selection of chain extender: Effect of increasing vicinity of urea linkages}

Chain extension has been comprehensively studied in polyurethanes, however such studies are rather scarce in the context of polyurea [9]. Increasing the amount of chain extender increases the hard segment content and is therefore expected to improve the tensile strength of the polymer. The chain extender increases the vicinity of the resultant urea groups, thereby increasing their probability of alignment to form H-bonds [10].
Diethyltoluenediamine is the most common aromatic chain extender for preparing spray processable polyurea formulations. In polyurea coatings prepared using DETDA chain extender [11], "toughness" was found to decrease with increasing soft segment content, with formulations containing higher hard segment (70\%) being relatively brittle. Spectroscopic techniques like IR and fluorescence have been used to study the formation of DETDA based chain extended polyurea coatings [12]. These studies reveal that although solidification occurs instantaneously, the entire 
process requires substantially longer periods ( $\sim 50$ minutes) for completion.

Studies by Iqbal et al. [6] have revealed that aromatic chainextenders are significantly more reactive than their aliphatic equivalents, which was confirmed by their significantly shorter 'gel-time' during rheological studies. Their studies further confirm that it is prudent to introduce a blend of aromatic and aliphatic chain extender. It appears that in the presence of a combination of these two, the growing macromolecule orients in a manner which results in optimal H-bonding $[12,13]$. It has also been found that the sub-zero glass transition temperature $\left(\mathrm{T}_{\mathrm{g}}\right)$ shifts methodically towards higher temperature as the total hard segment content decreased. It is to be noted that profile associated with the thermal decomposition of polyurea does not depend much on the type of extender employed. However, the mass losses associated with each of the two steps in the degradation profile is directly proportional to the proportion of hard and soft segment in the polymer.

\section{Selection of chemical crosslinker: Effect of introducing chemical crosslinking}

Although physical crosslinks (H-bonded urea linkages) are dispersed homogeneously throughout the entire matrix of polyurea, introduction of additional chemical crosslinking has been reported to bring about significant improvement in the chemical resistance as well as mechanical properties. Generally, in the context of polyurea and polyurethanes, crosslinking is introduced by inclusion of an amine with a functionality of more than 2 in the amine resin blend and/or by maintaining a slight excess of isocyanate $\left(\mathrm{i}_{\mathrm{NCO}}>1\right)$ [14]. By maintaining a slight excess of isocyanate, the latter can further react with the urethane and urea groups to form allophanate and biuret linkages respectively [15].

Short-chain crosslinkers such as 1,3,5 triaminophenoxylbenzene [16,17], bis(4-aminophenyl) disulphide [18], 0.0G PAMAM dendrimer [19] have been used to prepare polyurea films and their introduction have been reported to affect the tensile properties [20$22]$, swelling behavior $[22,23]$ as well as the thermal degradation profile of the polymer [21,24]. Interestingly, the amine resin blend of all commercial spray processable polyurea formulations includes a long-chain crosslinker. It has been observed that introducing these long chain crosslinkers lead to an increase in the tensile strength as well as storage modulus, but beyond an optimal crosslinking ratio, the mechanical strength decreased [25]. An extremely important role of the trifunctional amine is towards improving the chemical resistance of the polymer. In general, a relative decrease in the swelling index (in organic solvents) was observed with increasing crosslinking ratio. Interestingly introduction of long chain crosslinker did not affect the thermal degradation behaviour, as confirmed by thermogravimetric analysis.

It is clear that with this knowledge on the effect of varying the constituents of amine resin on the material properties of the coating, it is possible to design formulations with desired mechanical properties. However, there do exist some shortcomings. Firstly, most of the studies included in this review are based on the studies performed on polypropylene oxides with MDI based prepolymers. Detailed studies on aliphatic isocyanate based polyureas are not yet available in the open domain. In addition there are practically no studies on the effect of varying the composition on the weathering performance of polyurea coatings. In view of the above, studies in the aforementioned areas will continue to attract the attention of researchers in the years to come.

\section{References}

1. Iqbal N, Sharma PK, Kumar D, Roy PK (2018) Protective polyurea coatings for enhanced blast survivability of concrete. Construction and Building Materials 175: 682-690.

2. Iqbal N, Tripathi M, Parthasarathy S, Kumar D, Roy PK (2016) Polyurea coatings for enhanced blast-mitigation: a review. RSC Advances 6(111): 109706-109717.

3. Tripathi M, Parthasarathy S, Roy PK (2019) Mechanically robust polyurea nanofibers processed through electrospinning technique. Materials Today Communications 22: 100771.

4. Grujicic M, Pandurangan B, Bell WC, Cheeseman BA, Yen CF, et al. (2011) Molecular-level simulations of shock generation and propagation in polyurea. Materials Science and Engineering: A 528(10-11): 3799-3808.

5. Qiao J, Amirkhizi AV, Schaaf K, Nemat-Nasser S, Wu G (2011) Dynamic mechanical and ultrasonic properties of polyurea. Mechanics of Materials 43(10): 598-607.

6. Iqbal N, Tripathi M, Parthasarathy S, Kumar D, Roy PK (2018) Aromatic versus aliphatic: Hydrogen bonding pattern in chain-extended highperformance polyurea. Chemistry Select 3(7): 1976-1982.

7. Das S, Yilgor I, Yilgor E, Inci B, Tezgel O, et al. (2007) Structure-property relationships and melt rheology of segmented, non-chain extended polyureas: Effect of soft segment molecular weight. Polymer 48(1): 290301.

8. Iqbal N, Tripathi M, Parthasarathy S, Kumar D, Roy PK (2018) Tuning the properties of segmented polyurea by regulating soft-segment length. Journal of Applied Polymer Science 135(21): 46284.

9. Das S, Cox DF, Wilkes GL, Klinedinst DB, Yilgor I, et al. (2007) Effect of symmetry and H-bond strength of hard segments on the structureproperty relationships of segmented, nonchain extended polyurethanes and polyureas. Journal of Macromolecular Science, Part B: Physics 46(5): 853-875.

10. Toader G, Rusen E, Teodorescu M, Diacon A, Stanescu PO, et al. (2016) Novel polyurea polymers with enhanced mechanical properties. Journal of Applied Polymer Science 133(38).

11. Willkomm WR, Chen Z, Macosko C, Gobran DA, Thomas EL (1988) Properties and phase separation of reaction injection molded and solution polymerized polyureas as a function of hard block content. Polymer Engineering \& Science 28(14): 888-900.

12. Wang SK, Sung CSP (2002) Fluorescence and IR characterization of cure in polyurea, polyurethane, and polyurethane-urea. Macromolecules 35(3): 883-888.

13. Tripathi M, Parthasarathy S, Roy PK (2019) Spray processable polyurea formulations: Effect of chain extender length on material properties of polyurea coatings. Journal of Applied Polymer Science, p. 48573.

14. Chiou BS, Schoen PE (2002) Effects of crosslinking on thermal and mechanical properties of polyurethanes. Journal of Applied Polymer Science 83(1): 212-223.

15. Petrović ZS, Ferguson J (1991) Polyurethane elastomers. Progress in Polymer Science 16(5): 695-836. 
16. Shinko A, Jana SC, Meador MA (2015) Crosslinked polyurea aerogels with controlled porosity. RSC Advances 5(127): 105329-105338.

17. Shinko A, Jana SC, Meador MA (2018) Crosslinked polyurea-copolyurethane aerogels with hierarchical structures and low stiffness Journal of Non-Crystalline Solids 487: 19-27.

18. Martin R, Rekondo A, Ruiz de Luzuriaga A, Cabanero G, et al. (2014) The processability of a poly(urea-urethane) elastomer reversibly crosslinked with aromatic disulfide bridges. Journal of Materials Chemistry A 2(16): 5710-5715.

19. Tatiya PD, Mahulikar PP, Gite VV (2016) Designing of polyamidoaminebased polyurea microcapsules containing tung oil for anticorrosive coating applications. Journal of Coatings Technology and Research 13(4): 715-726.

20. Jung H, Kang S, Kim W, Lee YB, Choe K, et al. (2000) Properties of crosslinked polyurethanes synthesized from 4, 4'-diphenylmethane diisocyanate and polyester polyol. Journal of Applied Polymer Science 78(3): 624-630.
21. Desai S, Thakore I, Sarawade B, Devi S (2000) Effect of polyols and diisocyanates on thermo-mechanical and morphological properties of polyurethanes. European Polymer Journal 36(4): 711-725.

22. Ahmad N, Khan M, Ma X, Ul-Haq N (2014) The influence of cross-linking/ chain extension structures on mechanical properties of HTPB-based polyurethane elastomers. Arabian Journal for Science and Engineering 39(1): 43-51.

23.Špírková M, Matějka L, Hlavatá D, Meissner B, Pytela J (2000) Polybutadiene-based polyurethanes with controlled properties: preparation and characterization. Journal of Applied Polymer Science 77(2): 381-389.

24. Paulmer R, Shah C, Patni M, Pandya M (1991) Effect of crosslinking agents on the structure and properties of polyurethane millable elastomer composites. Journal of Applied Polymer Science 43(10): 1953-1959.

25. Iqbal N, Tripathi M, Parthasarathy S, Kumar D, Roy PK (2018) Polyurea spray coatings: Tailoring material properties through chemical crosslinking. Progress in Organic Coatings 123: 201-208.

For possible submissions Click below: 